\title{
Los estándares interpretativos de la Corte Interamericana de Derechos Humanos en materia de pena de muerte ${ }^{1}$
}

\section{The Interpretative Standards of the Inter-American Court of Human Rights in the matter of the Death Penalty}

\author{
Isaac Marcelo Basaure Miranda \\ isaacbasaure@gmail.com \\ Abogado por la Universidad Nacional de Lomas de Zamora (Buenos Aires, Argentina). Diplomado en \\ Derechos Económicos, Sociales y Culturales por la Secretaría de Derechos Humanos y Pluralismo \\ Cultural de la Nación en conjunto con la Universidad Nacional de la Patagonia San Juan Bosco.
}

Resumen: El presente artículo se propone identificar los principales estándares interpretativos aplicados por la Corte Interamericana de Derechos Humanos en materia de pena de muerte, para ello, se analizará la jurisprudencia que el órgano judicial ha dictado al respecto; teniendo como marco normativo a la Convención Americana sobre Derechos Humanos.

Palabras claves: Corte Interamericana de Derechos Humanos; pena de muerte; Convención Americana sobre Derechos Humanos; estándares interpretativos.

\begin{abstract}
The present paper intends to identify the main interpretive standards applied by the Inter-American Court of Human Rights in the matter of death penalty, for this purpose, the jurisprudence that the judicial body has dictated in this regard will be analysed; having as a normative framework the American Convention on Human Rights.
\end{abstract}

Keywords: Inter-American Court of Human Rights; Death Penalty; American Convention on Human Rights; Interpretative Standards.

1 Artículo enviado el 03.05.2018 y aceptado el 09.08.2018.

Número de página no utilizable para citar 
Los estándares interpretativos de la Corte Interamericana de Derechos Humanos en materia de pena de muerte Isaac Marcelo Basaure Miranda

\section{Introducción}

El día 22 de noviembre de 1969 los Estados americanos iniciaban un avance notable en materia de derecho internacional, al suscribir, en San José de Costa Rica, la Convención Americana sobre Derechos Humanos (en adelante $\mathrm{CADH}$ ). El precitado tratado dispuso, en virtud de su artículo $33^{2}$, la creación de la Corte Interamericana de Derechos Humanos (en adelante Corte IDH), un órgano judicial que detenta jurisdicción contenciosa para intervenir en causas legales en las que se examine el cumplimiento de las obligaciones internacionalmente asumidas por los Estados signatarios de la CADH. En el preámbulo de la CADH los Estados partes se han comprometido a consolidar en sus territorios, dentro del marco de la democracia, "un régimen de libertad personal y de justicia social, fundado en el respeto de los derechos esenciales del hombre"3; ahora bien, tal aseveración lleva implícita la protección y el reconocimiento del derecho más elemental del ser humano: el derecho a la vida. $\mathrm{La} \mathrm{CADH}$, en su artículo 4.1, lo consagra expresamente al sostener que: "toda persona tiene derecho a que se respete su vida"4. Por tanto, la adopción de la pena capital por parte de los Estados firmantes, representa una manifiesta violación del sistema interamericano de protección de los derechos humanos, siendo precisamente la CADH uno de sus pilares, junto con la Comisión Interamericana de Derechos Humanos (en adelante CIDH), y la Corte IDH. En efecto, la CADH reconoce al derecho a la vida como el bien jurídico más básico, necesario para que existan todos los demás. La importancia que el instrumento le otorga, puede verse reflejada en la privilegiada ubicación que ocupa: siendo el segundo derecho en reconocerse, luego del derecho al reconocimiento de la personalidad jurídica. Tal posición vino a ser reforzada por el Protocolo a la Convención Americana sobre Derechos Humanos relativo a la Abolición de la Pena de Muerte, aprobado en Paraguay, el 8 de junio de 1990 (en adelante Protocolo de 1990); en cuyo preámbulo se estableció que: "toda persona tiene el derecho inalienable a que se le respete su vida sin que este derecho pueda ser suspendido por ninguna causa”.

$\mathrm{La} \mathrm{CADH}$, en su artículo 4, prevé además una serie de restricciones orientadas a evitar la aplicación de la pena capital en los Estados que la han suscrito. La primera de ellas (artículo 4.2), está destinada a aquellos países que a la fecha de firmar la CADH incluían en su ordenamiento jurídico interno la pena de muerte —y que a la actualidad no la han abolido, como así tampoco se han adherido al Protocolo de 1990_, "ésta sólo podrá imponerse por los delitos más graves, en cumplimiento de sentencia ejecutoriada de tribunal competente y de conformidad con una

2 Artículo 33 de la CADH: "Son competentes para conocer de los asuntos relacionados con el cumplimiento de los compromisos contraídos por los Estados Partes en esta Convención: a) la Comisión Interamericana de Derechos Humanos, llamada en adelante la Comisión, y b) la Corte Interamericana de Derechos Humanos, llamada en adelante la Corte".

$3 \mathrm{CADH}$, preámbulo, segundo párrafo.

4 CADH, artículo 4.1.

Número de página no utilizable para citar 
ley que establezca tal pena, dictada con anterioridad a la comisión del delito. Tampoco se

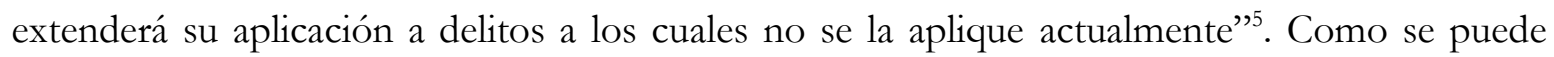
apreciar, la CADH aplica una interpretación restringida en materia de pena de muerte, buscando reducir los supuestos en los que es legítimo ejecutar el castigo; al mismo tiempo, procura asegurar las garantías penales básicas, como el debido proceso, la ley previa, y el principio de legalidad. La segunda restricción (artículo 4.36), dispone que la pena de muerte no podrá ser reestablecida en aquellos Estados signatarios que ya la han abolido; de modo que si un país la abolió antes o después de rubricar la CADH o el Protocolo de 1990, tiene prohibido restaurarla en su plexo jurídico. La tercera limitación (artículo $4.4^{7}$ ), es aquella que, de manera terminante, prohíbe la aplicación de la pena capital a delitos políticos o comunes conexos con los políticos; la CADH utiliza la expresión "en ningún caso", en consecuencia, tanto los Estados que han abolido la pena muerte, como aquellos en los que continua vigente, están obligados a respetar tal restricción. La cuarta prohibición (artículo $4.5^{8}$ ), recae sobre ciertas particularidades que presente la persona objeto de la pena de muerte, en concreto, no puede aplicarse a niños, es decir, menores de dieciocho años de edad de acuerdo con el paradigma establecido en el artículo 1 de la Convención sobre los Derechos del Niño'; asimismo, dicha pena tampoco puede aplicarse a ancianos (mayores de setenta años), ni a mujeres en estado de gravidez. Finalmente, la última limitación (artículo 4.6 $6^{10}$, consiste en otorgarle al sujeto condenado a muerte, el derecho a solicitar indulto, amnistía o la conmutación de la pena; en virtud de ello, la persona no puede ser condenada mientras la solicitud de condonación esté pendiente de resolución por autoridad competente.

Sucintamente expuesto, a modo introductorio, el panorama interamericano referido a la pena de muerte, resta mencionar que el conjunto de restricciones estipuladas por la $\mathrm{CADH}$ ha motivado, en la práctica judicial, diversas sentencias de la Corte IDH relativas a su interpretación, estableciendo determinados estándares interpretativos que serán identificados y desarrollados en las siguientes páginas.

CADH, artículo 4.2 .

Artículo 4.3 de la CADH: "No se reestablecerá la pena de muerte en los Estados que la han abolido". Artículo 4.4 de la CADH: "En ningún caso se puede aplicar la pena de muerte por delitos políticos ni comunes conexos con los políticos".

8 Artículo 4.5 de la CADH: "No se impondrá la pena de muerte a personas que, en el momento de la comisión del delito, tuvieren menos de dieciocho años de edad o más de setenta, ni se les aplicará a las mujeres en estado de gravidez".

9 Artículo 1 de la Convención sobre los Derechos del Niño: "Para los efectos de la presente Convención, se entiende por niño todo ser humano menor de dieciocho años de edad".

10 Artículo 4.6 de la CADH: "Toda persona condenada a muerte tiene derecho a solicitar la amnistía, el indulto o la conmutación de la pena, los cuales podrán ser concedidos en todos los casos. No se puede aplicar la pena de muerte mientras la solicitud esté pendiente de decisión ante autoridad competente".

Número de página no utilizable para citar 


\section{Primer antecedente interpretativo sobre la Pena de Muerte desarrollado por la Corte IDH: la Opinión Consultiva sobre las Restricciones a la Pena de Muerte (OC-3/83).}

El día 8 de septiembre de 1983, la Corte IDH emitió una opinión consultiva solicitada por la $\mathrm{CIDH}$, respecto a las restricciones que deben aplicarse a la pena de muerte. En este punto, resulta menester conceptualizar qué es una opinión consultiva: es una guía de interpretación o pautas desde donde se generan estándares de derechos humanos para toda la región sobre temas frente a los cuales es consultada la Corte IDH. Una de sus características es que reviste el carácter de obligatoriedad, es decir, son vinculantes para todos los Estados que hayan reconocido la competencia de la Corte IDH.

En la Opinión Consultiva OC3/83 ${ }^{11}$, el máximo tribunal interamericano de justicia analizó la interpretación que debe darse al segundo párrafo del artículo 4 de la CADH. El resultado de dicho examen determinó que debe fijarse una interpretación restrictiva a la facultad de aplicar la pena de muerte en aquellos Estados donde no ha sido abolida, toda vez que el bien jurídico tutelado por el artículo 4 de la $\mathrm{CADH}$, es el derecho a la vida, y es esa protección la que debe prevalecer, ya que ningún ser humano puede ser privado de la vida arbitrariamente, tal es lo que señala la $\mathrm{CADH}$ en su artículo 4.1. El criterio restrictivo, impuesto por la Corte IDH en la mentada Opinión Consultiva OC3/83, se sustenta, esencialmente, en tres grupos de limitaciones: en primer término, la aplicación de la pena capital debe cumplir, de manera estricta, con el conjunto de reglas procesales que el caso concreto exija; en segundo término, su ejecución debe quedar reducida, exclusivamente, a los delitos más gravosos, y que a su vez no guarden conexión con delitos políticos; y, en tercer lugar, debe atenderse a las consideraciones particulares de la persona del imputado, a fin de que, si las circunstancias lo ameritan, puedan emplearse para excluir la aplicación de la pena de muerte al detenido. Partiendo de éste insoslayable antecedente, se procederá, a continuación, a identificar los estándares interpretativos en materia de pena de muerte que la Corte IDH ha elaborado a través de su jurisprudencia.

11 Corte IDH, Opinión Consultiva OC3/83 del 8 de septiembre de 1983.

Número de página no utilizable para citar 


\section{Prohibición de aplicar la pena de muerte en forma automática $y$ obligatoria}

El primer caso contencioso sobre pena de muerte en el que la Corte IDH tuvo oportunidad de intervenir, fue el llamado: "Caso Hilaire, Constantine y Benjamin y otros vs. Trinidad y Tobago" "12, cuya sentencia data del 21 de junio de 2002. En él, la Corte IDH debió analizar la situación jurídica de treinta y dos presidiarios, quienes fueron hallados culpables de la comisión del delito de homicidio intencional, y, en virtud de la aplicación de la Ley de Delitos contra la Persona, sancionada el 3 de abril de 1925, vigente desde entonces en el ordenamiento legal trinitense, se los condenó a la pena de muerte; por lo que, agotados los recursos internos, acudieron a la Corte IDH. El tribunal interamericano concluyó en su sentencia, que Trinidad y Tobago debía abstenerse de utilizar la Ley de Delitos contra la Persona, por hallarla incompatible con los principios consagrados en la $\mathrm{CADH}$, ya que violaba sus artículos 4.1, y 4.2. La Corte IDH consideró que la colisión entre el tratado internacional y la norma interna, radicaba en que ésta última ordenaba la imposición automática de la pena capital a todos aquellos sujetos que cometieran el delito de homicidio intencional; sin ningún tipo de miramientos, sin considerar las circunstancias personales y las particularidades específicas de cada caso en concreto. De manera que se anulaba la discrecionalidad del juez para evaluar la existencia de posibles elementos atenuantes o agravantes. En el mismo sentido, la norma cuestionada producía una despersonalización del imputado, puesto que, al momento de calibrar la pena, sus características y antecedentes carecían por completo de valor, ya que la sanción era invariable e indiscutible: la pena de muerte obligatoria a todos aquellos que cometieran el delito de homicidio intencional. Dicha automatización de la condena, resultó entonces, violatoria de la $\mathrm{CADH}$, toda vez que: "elimina la posibilidad de razonar la individualización de la pena, impide establecer una conexión racional y proporcional entre el inculpado, el delito y el castigo impuesto y no permite una revisión judicial de la decisión adoptada" "13. Por ello, pese a que la pena capital se encontraba incluida en el sistema jurídico de Trinidad y Tobago con anterioridad a que el Estado suscribiera la $\mathrm{CADH}$, y continuara vigente después de su firma, ya que hasta entonces no la había abolido, la mentada Ley de Delitos contra la Persona conculcaba las disposiciones de los artículos 4.1 y 4.2 de la CADH, porque, al no considerar la coyuntura específica del acusado, como así tampoco las del delito, sesgaba cualquier posibilidad de graduación de la pena, privando arbitrariamente de la vida al sujeto: "al considerar a todo responsable del delito de homicidio intencional como merecedor de la pena capital se está tratando a los acusados de este crimen no como seres

12 Corte IDH, Caso Hilaire, Constantine y Benjamin y otros vs. Trinidad y Tobago, sentencia del 21 de junio de 2002, Serie C No. 94.

13 Corte IDH, Caso Hilaire..., p. 41.

Número de página no utilizable para citar 
Los estándares interpretativos de la Corte Interamericana de Derechos Humanos en materia de pena de muerte Isaac Marcelo Basaure Miranda

humanos individuales y únicos, sino como miembros indiferenciados y sin rostro de una masa que será sometida a la aplicación ciega de la pena de muerte"14.

De lo expuesto hasta aquí, se concluye que en los Estados en donde la pena de muerte está aún vigente, no basta con la sola existencia de una ley interna que la ejecute e implemente para que el castigo capital goce de plena validez, sino que dicha norma debe estar estrictamente en concordancia con las restricciones internacionales previstas por la $\mathrm{CADH}$ en su artículo 4, no pudiendo, en ningún caso, ser de aplicación arbitraria. Al mismo tiempo, se extrae que la pena capital no puede ser anticipadamente obligatoria, pues es menester evaluar primero las especificidades del caso concreto, a los fines de determinar si es procedente o no su aplicación. Así, por ejemplo, dentro de los treinta y dos condenados a la horca por parte del Estado de Trinidad y Tobago, se presentaba la singular situación del señor Amir Mowlah, quien padecía una afección psiquiátrica. El perito Nigel Eastman, psiquiatra forense, afirmó en su informe que posiblemente el acusado sufría de cierto desorden mental al momento de haber cometido el acto homicida. Como se observa, detalles tan sustanciales para alcanzar la posible atenuación de la pena, como lo es el caso de una enfermedad mental, fueron descartados por la justicia de Trinidad y Tobago al momento de determinar la culpabilidad en los enjuiciamientos por homicidio intencional.

El estándar interpretativo de la Corte IDH, según el cual debe rechazarse la naturaleza obligatoria de la pena de muerte, fue confirmado años más tarde en "Caso Raxcacó Reyes vs. Guatemala”, sentencia del 15 de septiembre de 2005. Dicha sentencia fue motivada por la condena a muerte del señor Ronald Raxcacó Reyes, quien había sido hallado penalmente responsable del delito de secuestro, cometido en contra de Pedro Alberto de León Wug, hecho que ocurrió el 5 de agosto de 1997. El 14 de mayo de 1999, el Tribunal Sexto de Sentencia Penal, Narcoactividad y Delitos contra el Ambiente de Guatemala, impuso la pena capital a Raxcacó Reyes, en virtud de que el delito cometido (el secuestro), es sancionado, conforme el artículo 201 del Código Penal guatemalteco, con la muerte. La Corte IDH consideró que el citado artículo era violatorio de la prohibición de privación arbitraria de la vida, consagrada en los artículos 4.1 y 4.2 de la CADH: "El artículo 201 del Código Penal, tal como está redactado, tiene como efecto someter a los acusados del delito de plagio o secuestro a procesos penales en los que no se consideran —en ninguna instancia - las circunstancias particulares del delito y del acusado, tales como los antecedentes penales de éste y de la víctima, el móvil, la extensión e intensidad del daño causado, las posibles circunstancias atenuantes o agravantes, entre otras consideraciones y del autor y del delito" ${ }^{\text {16 }}$. Por ello, la Corte IDH ordenó a Guatemala modificar el citado artículo para que se adecue a lo dispuesto por la $\mathrm{CADH}$, además de disponer una medida provisional, consistente en

14 Corte IDH, Caso Hilaire..., p. 45.

15 Corte IDH, Caso Raxcacó Reyes vs. Guatemala, sentencia del 15 de septiembre de 2005, Serie C No. 133.

16 Corte IDH, Caso Raxcacó..., p. 30.

Número de página no utilizable para citar 
la abstención por parte del Estado a ejecutar a los condenados hasta tanto no se haya modificado el artículo cuestionado.

Dos años más tarde, en "Caso Boyce y otros vs. Barbados"17, sentencia del 20 de noviembre de 2007, la Corte IDH reafirmó su postura contra la pena de muerte obligatoria. En cuanto a los hechos del caso, cuatro personas fueron condenadas a la horca, conforme al artículo 2 de la Ley de Delitos contra las Personas de 1994 de Barbados, el cual ordenaba la imposición forzosa de la pena de muerte a todo aquel que fuera hallado culpable del delito de homicidio. A semejanza de la Ley de Delitos contra la Persona de Trinidad y Tobago, la Corte IDH interpretó que la citada normativa de Barbados resultaba violatoria de los artículos 4.1 y 4.2 de la CADH, principalmente, porque se ordenaba la aplicación obligatoria de la pena de muerte, incurriendo en una arbitrariedad manifiesta. En consecuencia, se ejecutaba indiscriminadamente el mismo castigo penal a todas las situaciones, sin contemplar las distintas realidades jurídicas que cada caso es capaz de presentar. En éste sentido, la Corte IDH ha entendido que, aunque la norma sea legal, esto no significa que no pueda ser asimismo arbitraria: "una pena de muerte obligatoria legalmente impuesta puede ser arbitraria cuando la ley no distingue entre los distintos grados de culpabilidad del acusado ni toma en consideración las circunstancias particulares de cada delito" "18. Por consiguiente, si una persona es hallada culpable de la comisión de un delito de homicidio, y se la condena a la pena capital, sin posibilidad de que se le individualice su pena en atención a las circunstancias específicas que han rodeado al caso, se está perpetrando en contra de ella, una imposición clara de pena de muerte arbitraria. La ausencia de una esfera discrecional del juez, en la que se le permita graduar los diferentes niveles de culpabilidad del acusado, conforme a las particularidades propias de cada expediente, es lo que desencadena la arbitrariedad.

Finalmente, en "Caso Dacosta Cadogan vs. Barbados"19, sentencia del 24 de septiembre de 2009, la Corte IDH ratificó el estándar interpretativo que desaprueba la pena de muerte obligatoria. Se trataba, además, de una coyuntura similar a la presentada en el Caso Boyce y otros vs. Barbados, pues se cuestionaba la misma ley (Ley de Delitos contra las Personas de 1994): "La Corte ha sostenido que las referencias a los términos 'arbitrariamente' en el artículo 4.1 de la Convención y a 'delitos más graves' en el artículo 4.2 son incompatibles con las disposiciones que imponen obligatoriamente la pena de muerte a conductas que pueden variar considerablemente y que no restringen su aplicación a los delitos más graves" ${ }^{\prime 20}$.

17 Corte IDH, Caso Boyce y otros vs. Barbados, sentencia del 20 de noviembre de 2007, Serie C No. 169.

18 Corte IDH, Caso Boyce..., p. 16.

19 Corte IDH, Caso Dacosta Cadogan vs. Barbados, sentencia del 24 de septiembre de 2009, Serie C No. 204.

20 Corte IDH, Caso Dacosta..., p. 13. 


\section{Obligación de respetar el debido proceso legal}

Otro de los estándares interpretativos que la Corte IDH ha elaborado en el desarrollo de su jurisprudencia, en lo atinente a la pena de muerte, es el referido a la obligación que recae sobre los Estados signatarios de la CADH, de respetar las garantías judiciales y el principio de legalidad que el tratado contempla. En éste sentido, la Corte IDH, en "Caso Fermín Ramírez vs. Guatemala"21, sentencia del 20 de junio de 2005, condenó al Estado guatemalteco a efectuar un nuevo enjuiciamiento contra el señor Fermín Ramírez, puesto que su expediente judicial manifestaba severas deficiencias en el debido proceso legal. Al imputado en cuestión, el Ministerio Público Fiscal de Guatemala, le atribuyó la responsabilidad penal de haber cometido el delito de violación calificada, el cual, según el artículo 175 del Código Penal, está penado con prisión de 30 a 50 años; sin embargo, durante el juicio, el Tribunal interviniente informó a las partes acerca de una posible modificación en la calificación legal del delito (basándose en el artículo 333 del Código Procesal Penal), distinta de la contemplada hasta entonces. Luego de ello, en su alegato, el Ministerio Público determinó — sin haber solicitado jamás una reforma al auto de procesamiento- que Fermín Ramírez ya no era responsable por violación calificada, sino por asesinato (cuya pena es la muerte). El Tribunal aceptó entonces la nueva imputación, condenando a Fermín Ramírez al castigo capital. En este contexto, la Corte IDH entendió que tal cambio de carátula resultaba violatorio de los artículos 8.2.b) y 8.2.c) de la CADH; toda vez que al inculpado no se le notificó en ningún momento, que la nueva calificación jurídica consistía en el delito de asesinato, y que la consecuencia de tal sustitución, era la imposición de una pena más severa: la pena de muerte. De modo que no sólo se lo privó del derecho a suspender el debate oral, a los fines de ofrecer nuevas pruebas que permitieran contribuir a su absolución, sino que el Tribunal nunca procedió a tomarle una nueva declaración, conforme lo ordena el artículo 333 del Código Procesal Penal. Además, tampoco se le aclaró al imputado cuál había sido la nueva circunstancia que justificó el cambio en la calificación del delito. Se le impidió, entonces, que ejerciera su derecho a preparar su defensa en un tiempo razonable; en el mismo tenor, se lo despojó del derecho a ser fehacientemente notificado, de manera previa, del correspondiente cambio de carátula, por lo demás, tampoco se le aclaró, con anticipación, sobre qué delito recaía la nueva acusación, por el contrario, el imputado tomó conocimiento de ello en los alegatos finales del debate oral.

Por otro lado, la Corte IDH consideró que en el Caso Fermín Ramírez vs. Guatemala se había violado, además, el principio de congruencia entre la acusación y la sentencia. Dicha apreciación es clara de comprender, cuando al sujeto se lo ha imputado por un delito (violación calificada) y la sentencia resulta en la imposición de una figura penal completamente distinta, en este caso, el

21 Corte IDH, Caso Fermín Ramírez vs. Guatemala, sentencia del 20 de junio de 2005, Serie C No. 126.

Número de página no utilizable para citar 
asesinato. La Corte IDH afirma que es necesario fortalecer el principio de congruencia, uno de los elementos claves del debido proceso, ya que éste: "impide resoluciones judiciales al margen de la acusación formulada por un órgano ajeno al juzgador e independiente de éste" ${ }^{22}$. En la misma línea, el Tribunal interamericano señaló que el debido proceso "es el conjunto de requisitos que deben observarse en las instancias procesales a efecto de que las personas estén en condiciones de defender adecuadamente sus derechos ante cualquier acto del Estado que pueda afectarlos" ${ }^{23}$. De lo mencionado hasta aquí, podemos afirmar que, más allá de que la pena de muerte pueda ser legítima al estar tipificada en los códigos procesales y de fondo de un sistema jurídico, esto no significa que en un proceso contencioso, de tipo penal, deban desatenderse las garantías judiciales que integran el debido proceso. La pena capital, más allá de que se aplique a autores de delitos gravísimos, no habilita a soslayar el aseguramiento y ejercicio de las garantías procesales mínimas del acusado, ya sea por acción u omisión del Estado.

\section{La pena capital solo puede aplicarse a los delitos más graves}

La restricción referida a que la pena de muerte solo debe aplicarse a los delitos más graves, surge directamente del artículo 4.2 de la CADH. En el plano jurisprudencial, la Corte IDH ha tenido ocasión de reafirmar dicho principio en Caso Raxcacó Reyes vs. Guatemala. En el caso mencionado, la Corte IDH determinó que resultaba desproporcionada la aplicación de la pena de muerte al señor Raxcacó Reyes, quien no había cometido el delito de homicidio, sino el de secuestro. Ahora bien, cabe preguntarse en éste punto ¿cuáles son los delitos más graves que autorizan la imposición de la pena de muerte?, a los fines de responder a dicho interrogante, resulta necesario señalar que la Corte IDH comparte el criterio definido en la materia, por el Comité de Derechos Humanos de las Naciones Unidas. El Comité, en sus observaciones finales ${ }^{24}$ sobre la República Islámica de Irán, publicadas el 3 de agosto de 1993, sostuvo que la pena de muerte no puede imponerse a quienes hayan cometido delitos de carácter económico, corrupción y adulterio, o por delitos que no entrañan la pérdida de vidas humanas. Por lo tanto, los delitos más graves son aquellos que lesionan el bien jurídico de mayor tutela legal, es decir, el derecho a la vida; y la forma más común de atentar contra la vida humana, es el delito de homicidio. Por otro lado, el homicidio o asesinato, contempla en los diferentes códigos penales de los Estados miembros, diversos agravantes, como el homicidio agravado por el vínculo, por alevosía, el cometido para ocultar otro delito (criminis causae), entre otros. En definitiva, cuando el homicidio es calificado, es cuando adquiere su versión más gravosa, en consecuencia, la Corte

22 Corte IDH, Caso F. Ramírez..., p. 7.

23 Corte IDH, Caso F. Ramírez..., p. 3.

24 CCPR/C/79/Add.25, Observaciones del Comité de Derechos Humanos de la Organización de Naciones Unidas sobre República Islámica de Irán, 03.ag.1993.

Número de página no utilizable para citar 
Los estándares interpretativos de la Corte Interamericana de Derechos Humanos en materia de pena de muerte Isaac Marcelo Basaure Miranda

IDH sostiene que la pena capital debe quedar circunscripta, en líneas generales, a éste tipo penal: "En suma, los delitos más graves (...) que pueden ser sancionados con pena capital (en un Estado que retiene ésta y debe sujetar la retención a las estipulaciones de la CADH), son los homicidios calificados" $" 25$.

El estándar interpretativo de la Corte IDH, que restringe la aplicación de la pena de muerte sólo a los delitos más graves, también se expuso en Caso Hilaire, Constantine y Benjamin y otros vs. Trinidad y Tobago, principalmente, porque la Ley sobre Delitos contra la Persona del Estado trinitense, contemplaba la pena de muerte obligatoria para el delito de homicidio, sin distinguir los distintos niveles de gravedad y culpabilidad que puede presentar cada caso concreto, específicamente, no diferenciaba el homicidio simple del homicidio calificado, previendo para todos los tipos de homicidio intencional la misma retribución penal. Por ello, la Corte IDH interpretó que la Ley sobre Delitos contra la Persona: "dispone la llamada pena de muerte obligatoria para una amplia y heterogénea gama de conductas homicidas, en las que objetivamente sería posible identificar (...) distintos grados de culpabilidad. Con ello se desatiende la regla de que la pena de muerte solo podrá imponerse por los delitos más graves"26.

\section{Limitación progresiva de la pena de muerte}

La serie de restricciones elaboradas por la $\mathrm{CADH}$ a la pena de muerte, persiguen el objetivo de limitar, progresivamente, la aplicación de la pena en los Estados firmantes. Dicha tendencia encuentra sus fundamentos en el artículo 4.3 del tratado, el cual prohíbe el reestablecimiento de la pena capital en los países que ya la han abolido; y en el artículo 4.2, en el que se dictamina que tal sanción no podrá extenderse a otros delitos sobre los cuales, al momento de firmarse la CADH, el Estado parte no aplicaba la pena de muerte. La Corte IDH, en Caso Hilaire, Constantine y Benjamin y otros vs. Trinidad y Tobago, confirmó claramente el espíritu abolicionista de la $\mathrm{CADH}$, al declarar que las normas convencionales sobre la pena de muerte "deben interpretarse en el sentido de limitar definitivamente su aplicación y su ámbito, de modo que éste se vaya reduciendo hasta su supresión final" ${ }^{27}$. En virtud de ello, la Corte IDH entiende que la normativa de la CADH debe analizarse "conforme al principio propersona, es decir, a favor del individuo"28. El principio pro persona establece que, presentada la disyuntiva de decidir judicialmente que ley debe aplicarse al imputado, es menester optar por aquella que contemple la mayor protección jurídica desde la visión de los derechos humanos. De modo que es "un

25 Corte IDH, Caso Raxcacó..., p. 7.

26 Corte IDH, Caso Hilaire..., p. 8.

27 Corte IDH, Caso Hilaire..., p. 43.

28 Corte IDH, Caso Boyce..., p. 15.

Número de página no utilizable para citar 
criterio hermenéutico que rige al derecho en materia de derechos humanos que consiste en preferir la norma o criterio más amplio en la protección de derechos humanos y la norma o criterio que menos restrinja el goce de los mismos" (Bahena, 2015: p. 7).

El estándar limitativo que efectúa la Corte IDH, en éste aspecto, también ha quedado plasmado en Caso Raxcacó Reyes vs. Guatemala, aquí, se constató que el Estado guatemalteco violó el artículo 4.2 de la $\mathrm{CADH}$, ya que amplió el catálogo de conductas delictivas castigadas con la pena de muerte. Guatemala, luego de ratificar la $\mathrm{CADH}$, por medio de una serie de reformas legislativas fue modificando el artículo 201 de su Código Penal, hasta incluir nuevos supuestos de aplicación de la pena capital; concretamente, el artículo 201 preveía en 1978 — fecha en que Guatemala ratificó la CADH - la pena de muerte para el que cometiera el delito de secuestro seguido de muerte, es decir, aquella situación en la que el individuo secuestrado perdiera la vida; sin embargo, dicha pena no se aplicaba al que cometiera exclusivamente secuestro. En el año 1996, mediante Decreto Legislativo No. 81/96, Guatemala modificó el citado artículo; la nueva redacción, entonces, prescribía la pena de muerte a todo aquel que fuera hallado penalmente responsable del delito de secuestro, aunque no haya mediado la muerte de la víctima, ampliando el espectro punitivo.

Por ello, la Corte IDH condenó a Guatemala a modificar el artículo 201 del Código Penal: "Esta modificación en ningún caso ampliará el catálogo de delitos sancionados con la pena capital previsto con anterioridad a la ratificación de la Convención Americana"29. Por lo expuesto, la Corte IDH manifiesta un claro rechazo a la decisión de expandir el ámbito de aplicación de la pena de muerte.

\section{Derecho del condenado a solicitar indulto, amnistía o conmutación de pena}

El artículo 4.6 de la CADH otorga el derecho a toda persona condenada a pena capital, a peticionar clemencia a las autoridades internas. Dicha prerrogativa cuenta, además, con una medida provisional: mientras la solicitud esté pendiente de resolución ante autoridad competente, no podrá procederse a ejecutar la pena. En virtud de tal disposición, los Estados tienen la obligación de asegurar a los condenados a muerte el acceso a la petición de gracia. En Caso Fermín Ramírez vs. Guatemala, la Corte IDH tuvo la oportunidad de confirmar éste precepto. El señor Fermín Ramírez, sentenciado a la pena capital por habérsele atribuido la comisión del delito de violación calificada y asesinato, interpuso, amparándose en el artículo 4.6

29 Corte IDH, Caso Raxcacó..., p. 43.

Número de página no utilizable para citar 
Los estándares interpretativos de la Corte Interamericana de Derechos Humanos en materia de pena de muerte Isaac Marcelo Basaure Miranda

de la CADH, el recurso de indulto. El Decreto No 159, del 19 de abril de 1892, concedió al Presidente de la República de Guatemala la facultad de otorgar o denegar indultos. No obstante ello, el Decreto No 32/2000 del 1 de junio de 2000, ordenó la derogación del Decreto No 159, despojando al Presidente de su aptitud para intervenir en materia de indultos. La defensa legal de Fermín Ramírez requirió el indulto el día 27 de julio de 1999, valiéndose del Decreto $\mathrm{N}^{\circ} 159$, sin embargo, la solicitud no fue resuelta por el Presidente sino hasta un día después de que apareciera publicado en el Diario Oficial el Decreto 32/2000, que establecía la derogación del Decreto $N^{\circ} 159$. De modo que a la fecha en que el Presidente determinó rechazar el indulto, ya no poseía la facultad para hacerlo; en palabras de la Corte IDH: "No existía en Guatemala regulación del indulto al momento en que se resolvió la petición de gracia del señor Fermín Ramírez, por lo que tanto el procedimiento como la decisión fueron arbitrarios" ${ }^{30}$. De lo que se desprende que, la ausencia de una legislación interna vigente que garantice al condenado su derecho a peticionar indulto, amnistía o conmutación de la pena, constituye una evidente violación al artículo 4.6 de la CADH. Asimismo, la Corte IDH hace observar que la mera aceptación del recurso de gracia, no supone, necesariamente, que el órgano estatal encargado de otorgarlo lo conceda, pues debe tenerse presente que la naturaleza del indulto es facultativa. Por todo ello, el indulto "no debe quedar exento de reglas precisas acerca de la autoridad llamada a concederlo, los fundamentos para otorgarlo y el procedimiento para resolverlo"31. El vacío legal del indulto en Guatemala también fue condenado en Caso Raxcacó Reyes vs. Guatemala, con idéntica postura: "la adopción, dentro de un plazo razonable, de un procedimiento que garantice que toda persona condenada a muerte tenga derecho a solicitar y, en su caso, obtener indulto o conmutación de pena, conforme a una regulación que establezca la autoridad facultativa para concederlo, los supuestos de procedencia y el trámite respectivo".32

\section{Prohibición de extraditar cuando exista riesgo de pena de muerte}

Hasta la fecha, el último expediente contencioso que tuvo como eje la pena de muerte, dentro de la jurisprudencia de la Corte IDH, es "Caso Wong Ho Wing vs. Perú"33, sentencia del 30 de junio de 2015. En ésta oportunidad, el objeto de la controversia recayó en si el Estado peruano debía proceder, o no, a la extradición del señor Wong, ciudadano chino, a la República Popular de China. En el año 2008, el señor Wong fue detenido en el Aeropuerto Internacional Jorge Chávez de la ciudad de Lima, Perú; en virtud de un pedido de captura internacional solicitado por las autoridades de Hong Kong a INTERPOL, donde se lo acusaba de haber cometido el

30 Corte IDH, Caso F. Ramírez..., p. 56.

31 Corte IDH, Caso F. Ramírez..., p. 10.

32 Corte IDH, Caso Raxcacó..., p. 44.

33 Corte IDH, Caso Wong Ho Wing vs. Perú, sentencia del 30 de junio de 2015, Serie C No. 297.

Número de página no utilizable para citar 
delito de contrabando de mercancías. La precitada conducta delictiva se hallaba tipificada en el artículo 151 del Código Penal de China, previendo como sanción la pena de muerte. En el ámbito interamericano, existe la Convención Interamericana para Prevenir y Sancionar la Tortura, cuyo artículo 13 , último párrafo ${ }^{34}$, prohíbe la extradición de la persona al país requirente cuando exista presunción fundada de que su devolución implique un riesgo para su vida; Perú se encuentra obligado a respetar dicho tratado, ya que lo ha suscrito el 10 de enero de 1986, ratificándolo el 27 de febrero de $1990^{35}$. En consecuencia, el 24 de mayo de 2011, el Tribunal Constitucional de Perú ordenó al Poder Ejecutivo peruano que se abstenga de llevar a cabo la extradición, argumentando que: "Las garantías diplomáticas ofrecidas por la República Popular China son insuficientes para garantizar que al señor Wong Ho Wing no se le va a aplicar la pena de muerte" ${ }^{36}$. Sin embargo, el 1 de mayo de 2011 entró en vigencia en China la octava enmienda del Código Penal, la cual derogó la pena de muerte para el delito de contrabando por el cual estaba siendo sometido a extradición el señor Wong. A pesar de ello, el Tribunal Constitucional consideró que tal modificación no fue comunicada ni incluida oficialmente en el expediente, por las vías diplomáticas adecuadas, de modo que no fue tenida en cuenta. No obstante, la sentencia del Tribunal Constitucional no implicó la puesta en libertad del acusado, sino que, el Estado peruano, continuó extendiendo arbitrariamente la privación de la libertad del señor Wong de manera excesiva.

La prolongación indefinida del proceso de extradición hizo que la CIDH presentase el caso ante la Corte IDH; quien declaró que Perú era responsable de la violación de la garantía del plazo razonable, asegurada por la CADH en su artículo $8.1^{37}$. Por otro lado, consideró que, al derogar China la pena de muerte para el delito de contrabando, se eliminaba la posibilidad de que al señor Wong se le aplique la pena de muerte, y, por ende, debía procederse a su inmediata extradición: “actualmente no sería legalmente posible la aplicación de pena de muerte (...) por lo cual, en caso de extraditarse al señor Wong Ho Wing, el Estado no sería responsable de una violación de su obligación de garantizar sus derechos a la vida e integridad personal" ${ }^{38}$. Al margen de la solución adoptada por la Corte IDH en el presente caso, lo sustancial de la sentencia, a los fines de identificar estándares interpretativos, es que se confirma el principio de no extradición,

34 Artículo 13, último párrafo, de la Convención Interamericana para Prevenir y Sancionar la Tortura: "No se concederá la extradición ni se procederá a la devolución de la persona requerida cuando haya presunción fundada de que corre peligro su vida, de que será sometido a tortura, tratos crueles, inhumanos o degradantes o de que será juzgada por tribunales de excepción o ad hoc en el Estado requirente".

35 Convención Interamericana para Prevenir y Sancionar la Tortura, Cartagena de Indias, 9 de diciembre de 1985, Serie sobre Tratados OEA, No 67, https://www.cidh.oas.org/Basicos/Spanish/Basicos3a.htm [consulta: 02 de mayo de 2018].

36 Corte IDH, Caso Wong Ho Wing..., p. 27.

37 Artículo 8.1 de la CADH: "Toda persona tiene derecho a ser oída, con las debidas garantías y dentro de un plazo razonable, por un juez o tribunal competente, independiente e imparcial, establecido con anterioridad por la ley, en la sustanciación de cualquier acusación penal formulada contra ella, o para la determinación de sus derechos y obligaciones de orden civil, laboral, fiscal o de cualquier otro carácter".

38 Corte IDH, Caso Wong Ho Wing..., p. 105. 
Los estándares interpretativos de la Corte Interamericana de Derechos Humanos en materia de pena de muerte Isaac Marcelo Basaure Miranda

cuando exista presunción fundada para creer que el sujeto estaría en peligro de ser sometido a muerte, tortura, u otros tratos inhumanos o degradantes en el Estado requirente. En la misma línea, la Corte IDH sostiene que el principio de no devolución se aplica a todas las modalidades de devolución de una persona a otro Estado, incluso por extradición. Por otra parte, la Corte IDH establece que con el objetivo de asegurar el derecho a la vida, "los Estados que han abolido la pena de muerte no pueden exponer a una persona bajo su jurisdicción al riesgo real y previsible de su aplicación, por lo cual no pueden expulsar, por deportación o extradición, a las personas bajo su jurisdicción si se puede prever razonablemente que pueden ser condenadas a muerte" 39 . Tal prohibición también rige para los Estados que aún no han abolido la pena de muerte, con la salvedad de que, éstos últimos, pueden aplicar la pena capital dentro de su territorio, sólo para sancionar los delitos más graves. Por ello, la Corte IDH solicita a los Estados que han sido requeridos para otorgar una extradición, ya sea que hayan abolido o no la pena de muerte, que exijan las garantías suficientes de que la pena capital no le será aplicada al extraditado.

\section{Breve jurisprudencia del Tribunal Europeo de Derechos Humanos en materia de pena de muerte}

Hasta aquí se han identificado y desarrollado los principales lineamientos que la Corte IDH ha adoptado en materia de pena de muerte, sin embargo, resulta oportuno examinar, brevemente, algunos casos jurisprudenciales del Tribunal Europeo de Derechos Humanos (en adelante TEDH), con el objeto de brindar una visión más global desde el punto de vista del derecho comparado. Aquí, primeramente, es preciso observar que en el ámbito del Consejo de Europa ${ }^{40}$, la pena de muerte ha sido abolida. Tal es lo que recepta el Convenio Europeo de Derechos Humanos (en adelante $\mathrm{CEDH}$ ) en su Protocolo No6, artículo 1: "Queda abolida la pena de muerte. Nadie Podrá ser condenado a tal pena ni ejecutado”.

Del análisis somero de la jurisprudencia europea surgen algunas coincidencias, así, por ejemplo, en "Caso Soering vs. Reino Unido" 41 del 7 de julio de 1989, el TEDH acogió el principio de no extradición cuando exista riesgo de pena de muerte en el país requirente. En la citada causa judicial, el Gobierno de Estados Unidos solicitó al Gobierno Británico la extradición de Jens

39 Corte IDH, Caso Wong Ho Wing..., p. 44.

40 El Consejo de Europa, con sede en Estrasburgo (Francia), es una organización intergubernamental de la que forman parte 47 Estados europeos. Fue fundada por el Tratado de Londres de 5 de Mayo de 1949 que establece que: "La finalidad del Consejo de Europa consiste en realizar una unión más estrecha entre sus miembros para salvaguardar y promover los ideales y los principios que constituyen su patrimonio común y favorecer su progreso económico y social". Estos ideales y principios se estructuran en los pilares de Derechos Humanos, Democracia y Estado de Derecho, que son el eje principal del trabajo de la Organización.

41 TEDH, Caso Soering vs. Reino Unido, sentencia del 7 de julio de 1989, Nº 14038/88. 
Soering por haber cometido el delito de homicidio en el Estado de Virginia (USA). Así las cosas, Jens Soering recurrió al TEDH para impedir ser extraditado. Su petición se basaba en que, en caso de hacerse efectiva la extradición a Estados Unidos, con certeza se le aplicaría la pena capital. Allí se lo ubicaría en el llamado "corredor de la muerte" sector carcelario donde los reclusos son confinados a la espera de que se ejecute la pena capital. Tal situación de espera la cual puede extenderse en el tiempo durante varios años-, configuraría, según el TEDH, la comisión por parte del Estado requirente de penas o tratos inhumanos o degradantes, en atención al constante sufrimiento mental que padecería el detenido, al ser consciente de que, en cualquier momento, puede ser citado para que se ejecute sobre su persona la pena de muerte. El TEDH consideró que la precitada coyuntura implicaría la violación del artículo 3 del CEDH, según el cual: "Nadie podrá ser sometido a tortura ni a penas o tratos inhumanos o degradantes" ${ }^{\prime 2}$. Por todo ello, se negó la extradición del señor Soering a Estados Unidos. La posición jurisprudencial del TEDH, en ésta materia, se vio reforzada años después, en "Caso Jabari vs. Turquía"43 del 11 de octubre de 2000, donde el TEDH negó la extradición de una ciudadana iraní a Irán, debido a que tal procedimiento la expondría a ser dilapidada hasta la muerte por haber cometido el delito de adulterio.

Por otro lado, en "Caso Öcalan vs. Turquía" del 12 de mayo de 2005, el TEDH determinó la obligación que tienen los Estados europeos de respetar el debido proceso y las garantías procesales más elementales. En el caso en cuestión, el señor Abdullah Öcalan fue sentenciado el día 29 de junio de 1999 por la Corte de Seguridad Estatal de Ankara, Turquía, a la pena de muerte. "En su Sentencia, la Corte de Seguridad Estatal de Ankara le consideró culpable de realizar actos diseñados para causar la secesión de una parte del territorio de Turquía" (Bou, 2004: p. 1). Sin embargo, en octubre de 2001, Turquía modificó el artículo 38 de su Constitución Nacional, estableciendo que la pena de muerte sólo podrá dictarse en tiempos de guerra, peligro inminente de guerra o por actos de terrorismo, por tanto se le conmuto la pena capital por la de cadena perpetua. El ciudadano turco apeló la decisión ante el TEDH, quien consideró violentado el artículo $6.1^{45}$ del CEDH, el cual garantiza el derecho a un proceso equitativo. El TEDH concluyó que la composición militar del Tribunal de Seguridad de Ankara afectó la imparcialidad e independencia que debe revestir un tribunal. En consecuencia, el TEDH afirmó que la

42 Convenio Europeo de Derechos Humanos, Roma, 4 de noviembre de 1950, artículo 3.

43 TEDH, Caso Jabari vs. Turquía, sentencia del 11 de octubre de 2000, No 40035/98.

44 TEDH, Caso Öcalan vs. Turquía, sentencia del 12 de mayo de 2005, No ${ }^{\circ} 46221 / 99$.

45 Artículo 6.1 del CEDH: “Toda persona tiene derecho a que su causa sea oída equitativa, públicamente y dentro de un plazo razonable, por un tribunal independiente e imparcial, establecido por la ley, que decidirá los litigios sobre sus derechos y obligaciones de carácter civil o sobre el fundamento de cualquier acusación en materia penal dirigida contra ella. La sentencia debe ser pronunciada públicamente, pero el acceso a la sala de audiencia puede ser prohibido a la prensa y al público durante la totalidad o parte del proceso en interés de la moralidad, del orden público o de la seguridad nacional en una sociedad democrática, cuando los intereses de los menores o la protección de la vida privada de las partes en el proceso así lo exijan o en la medida considerada necesaria por el tribunal, cuando en circunstancias especiales la publicidad pudiera ser perjudicial para los intereses de la justicia".

Número de página no utilizable para citar 
imposición de la pena capital como consecuencia de un juicio injusto implica una violación inadmisible del CEDH, por ello se condenó a Turquía por no garantizar a Abdullah Öcalan un juicio imparcial.

Finalmente, en "Caso Al-Saadoon y Mufdhi vs. Reino Unido" "46, del 2 de marzo de 2010, el TEDH denegó la extradición de dos ciudadanos iraquíes quienes se hallaban dentro de la jurisdicción de Reino Unido, por considerar que, de ser transferidos a las autoridades iraquíes, serían, probablemente, víctimas de la pena de muerte por ahorcamiento. Aquí, el TEDH estableció que la pena de muerte es un trato inhumano y degradante, dado que implica la destrucción deliberada y premeditada de un ser humano por parte de las autoridades estatales, causando dolor físico e intenso sufrimiento psicológico como consecuencia de la aplicación de la muerte, resultando violatoria del artículo 3 del $\mathrm{CEDH}$.

\section{Conclusión}

A modo de colofón, podemos señalar que los estándares interpretativos de la Corte IDH, en materia de pena de muerte, representan un estricto método de cumplimiento de las restricciones previstas en la $\mathrm{CADH}$, hecho que queda demostrado por medio de las distintas condenas a los Estados miembros que las han violado. La prohibición de aplicar la pena de muerte obligatoria, impone a los Estados el deber de generar procesos judiciales que permitan individualizar la pena, interpretar las circunstancias en las que el acto delictivo fue cometido, los antecedentes y condiciones del imputado; de manera que se evite la automatización de la justicia, es decir, la aplicación indiscriminada de la pena de muerte a todos aquellos que hayan cometido determinado delito, sin poner bajo tela de juicio el contexto específico que rodea al acto criminal. Es necesario, antes de sancionar, tener una comprensión global de los hechos que se discuten, valorar los elementos atenuantes y agravantes; se debe aplicar, además, el principio pro persona, en la medida de lo posible, porque es necesario someter a evaluación la posibilidad de optar por aquellas medidas judiciales que resulten menos lesivas para la dignidad humana. Los Estados deben, asimismo, asegurar el debido proceso, consagrado a través del respeto a una serie de garantías básicas: el principio de legalidad, la ley previa, el derecho a la defensa, la irretroactividad de la ley penal, ser juzgado por un tribunal competente creado con anterioridad al hecho del proceso, el principio de congruencia, el derecho a solicitar indulto, y demás garantías judiciales contempladas por el artículo 8 de la $\mathrm{CADH}$, toda vez que la pena de muerte, una vez ejecutada, es irreversible. En el mismo sentido, la Corte IDH circunscribe la aplicación de la pena de muerte sólo a los delitos de máxima gravedad. Su jurisprudencia ha determinado que éstos últimos son

46 TEDH, Caso Al-Saadoon y Mufdhi vs. Reino Unido, sentencia del 2 de marzo de 2010, Nº 61498/08.

Número de página no utilizable para citar 
los que implican la pérdida de la vida humana, en concreto, los homicidios calificados. Por otro lado, debe garantizarse el derecho a interponer el recurso de indulto ante autoridad competente a todos los condenados a muerte. De igual modo, en un proceso de extradición, se debe respetar el principio de no devolución, consistente en negar la extradición del acusado al país requirente cuando ésta implique un riesgo real para su vida, materializado en la inminente aplicación de la pena de muerte por el delito del que se le acusa.

Finalmente, se destaca la inclinación abolicionista que plantea la Corte IDH en cada uno de sus fallos relativos a la pena de muerte, la regla es estudiar cada una de las restricciones ordenadas por la CADH, a los fines de reducir al máximo posible su aplicación. La eliminación de la pena de muerte traerá aparejado, sin dudas, un robustecimiento de la $\mathrm{CADH}$, toda vez que, uno de sus objetivos es la abolición de la pena capital, sin embargo, en la actualidad, aún estamos lejos de materializar dicho objetivo. En éste punto, resulta menester concluir que, la $\mathrm{CADH}$, no prohíbe la pena de muerte a los Estados miembros que al momento de suscribir la convención la incluían en sus ordenamientos jurídicos; sólo está vetada para los países que a la fecha de firmar ya la habían abolido o no la contemplaban en su sistema legal. Ello se debe a que la CADH no fue lo suficientemente lucida como para plantear la abolición definitiva de la pena de muerte en todos los países signatarios, quizás no estaban las condiciones dadas; pero lo cierto es que no se les exigió a los Estados que ya habían adoptado la pena capital a la fecha de la firma, que adecuasen sus respectivos plexos jurídicos bajo el paradigma abolicionista. Éste es el motivo por el cual la pena de muerte continúa vigente en algunos Estados partes de la CADH, y, por tanto, dicha permanencia de la pena ha obligado a la Corte IDH a expedirse sobre la temática, estableciendo estándares interpretativos orientados a alcanzar la abolición definitiva de la pena capital.

\section{Referencias bibliográficas}

BAHENA, Alma Rosa (2015). "El principio pro persona en el estado constitucional y democrático de derecho", Revista Ciencia Jurídica, 4(7): 7-28.

Bou Franch, Valentín (2004). "Reflexiones sobre la pena de muerte en el asunto Öcalan C. Turquía”, Revista Electrónica de Asuntos Internacionales (REEI), (8). 